\title{
Entre tradições historiográficas: um estudo de Georges Duby
}

\section{Between historiographical traditions: a study of Georges Duby}

COSTA, Milton Carlos. Compreender Georges Duby: introdução à obra de um medievalista dos Annales. São Paulo: Alameda, 2015. 366p.

\section{Thiago Henrique Sampaio}

thiago.sampaio92@gmail.com

Mestrando em História

UNESP/Assis

Av. Dom Antônio, 2100 - Parque Universitário

19806-900 - Assis - SP Brasil

Brasil

Palavras-chave

Annales; Campo historiográfico; Historiografia.

Keywords

Annales; Historiographical field; Historiography. 
Compreender Georges Duby, título mais eloquente não poderia ser dado para uma análise cujo foco é a trajetória de um dos medievalistas franceses mais importantes do século XX. Através da reflexão sobre a produção historiográfica, depoimentos e entrevistas, Milton C. Costa, historiador e professor livre-docente da Faculdade de Ciências e Letras da UNESP/Assis, traz Duby ao centro do debate que toma a historiografia contemporânea como elemento de análise.

De acordo com Milton C. Costa, sua motivação para realizar a obra resulta de sua tese de livre-docência, quando percebeu a falta de estudos aprofundados sobre Duby, tanto no contexto nacional quanto no internacional. O autor prioriza a abordagem histórica, encetada pelo historiador francês em questão, dentro dos Annales e na tentativa de construir uma história mais próxima do homem e de sua comunidade.

O livro divide-se em nove capítulos, além do prefácio, introdução e considerações finais. Da mesma maneira, é possível analisar o livro em três unidades, nas quais a primeira, constituída pela introdução e os dois primeiros capítulos, em que buscou apresentar a trajetória do historiador. Evidenciando o percurso desenvolvido por Duby na sua formação, suas principais influências e seus mentores.

Na segunda parte, constituída do terceiro ao sexto capítulo, o autor elencou as principais obras de Duby, buscou discuti-las dentro do panorama historiográfico da sua elaboração, suas motivações ao escrevê-las e a originalidade.

A terceira unidade, composta pelo sétimo ao nono capítulo, por sua vez, 186 demonstrou a recepção e a convivência do medievalista com outros historiadores de seu tempo. Desta forma, é exposta a relação de Duby com seus contemporâneos na construção e revisão da historiografia sobre o período medieval.

$\mathrm{Na}$ Introdução, Milton C. Costa demonstrou de forma sistemática e seletiva as obras de Georges Duby, objetivando expor um panorama global da obra do medievalista.

Intitulado A trajetória historiográfica de Georges Duby, o capítulo primeiro recuperou a trajetória do historiador através de suas obras, depoimentos e entrevistas. Foram mostrados os principais autores que influenciaram Duby em sua formação, como Marc Bloch, Jean Deniau, Leon Homo e Lucien Febvre. Além deles, Milton C. Costa evidenciou que para entendermos a produção deste medievalista é fundamental percebermos seus contatos com as Ciências Sociais, a produção de Marx e a Geografia de André Allix.

Em sua trajetória como historiador, Duby recebeu forte influência de seu orientador Charles Edmond Perrin. Ação que foi decisiva para sua busca por uma História Social que compreendesse a sociedade como um sistema de elementos solidários estruturados e paisagens como uma forma de conhecimento histórico. Ademais, também sofreu forte influência da obra $A$ sociedade feudal de Marc Bloch ao longo de sua história pessoal.

Junto com Robert Mandrou desenvolveu o legado de Lucien Febvre sobre a História das Mentalidades. Ao final do capítulo foi evidenciada a mudança na sua formação historiográfica a partir da obra As três ordens, na qual contou com a colaboração de Le Goff para sua confecção. 
No capítulo seguinte, Duby: teoria, método, historiografia, mostrou-se o pensamento do medievalista a respeito das questões pertinentes ao ofício de historiador. O autor expõe as mudanças ocorridas na produção de Georges Duby ao longo de suas obras. Em seu livro Diálogos sobre a Nova História, Duby faz críticas à produção historiográfica de Jules Michelet e grandes elogios à história produzida por Fustel de Coulanges e Augustin Thierry. A importância que teve o método quantitativo no fazer histórico de Duby foi levantada por Milton C. Costa.

Para o autor, Duby possuía uma forte dívida com os Annales, pois sua história foi construída através do princípio de colaboração com as ciências sociais e de que o historiador deveria fugir de teorias paralisantes, pouco aplicadas em seus temas. Sofreu forte influência das três temporalidades de Braudel e do espaço geográfico na construção de sua História das Mentalidades. Em seu livro Ano Mil (1967), Georges Duby começou a colocar em prática os princípios da História das Mentalidades, através dos quais analisou as estruturas materiais decorrentes das construções humanas, fundamentais na edificação de uma História Social.

No terceiro capítulo, A economia política do feudalismo, foi dada uma visão global do livro Guerreiros e Camponeses, na qual são analisados os primórdios do crescimento econômico europeu do século VII ao XII. Com esta obra, Duby encerrou seus estudos dedicados a problemas econômicos e sociais da Europa Medieval, pois posteriormente adentraria aos estudos sobre as mentalidades.

No capítulo seguinte, Sociedades e sociabilidades medievais: o parentesco, as mulheres, o casamento, Milton C. Costa buscou entender as relações sociais trabalhadas por Duby e, principalmente, a figura das mulheres no meio medieval. Nesta fase, o medievalista avançou sua entrada na História das Mentalidades com o apoio da semiologia e antropologia na sua escrita histórica.

Para entender a mulher no período medieval, Duby apoia-se em algumas figuras como Heloísa (Heloísa e Pedro Abelardo), Isolda (Tristão e Isolda), Eva e Maria Madalena, cada uma mostrava um ideal de mulher a ser seguido por aquela sociedade. Por sua vez, o medievalista analisou o feminino como um local de estranheza dentro da era medieval, assim como as relações cabíveis às mulheres daquela ordenação social (casamento, educação, luto).

No quinto capítulo, O universo político medieval: poder, ideologia, imaginário, são apresentadas duas grandes obras de Georges Duby: Guilherme Marechal, ou o melhor cavaleiro do mundo e, uma das suas mais importantes e ambiciosas obras, As três ordens ou o imaginário do feudalismo. A primeira delas apresentou a figura de Guilherme Marechal, um grande senhor feudal, e a cavalaria, instituição da qual ele fez parte. Nesta obra, o medievalista buscou relançar luz ao funcionamento político do sistema feudal e sua principal base de sustentação: a cavalaria. Guilherme Marechal ficou eternizado através de uma canção de gesta, pois seus descendentes julgaram necessário preservar a memória do fundador de sua linhagem. Ao analisar a cavalaria, Duby mostrou que ela tinha uma cultura própria, na qual as canções tiveram um importante destaque.

Na segunda parte, onde se aborda a obra As três ordens ou o imaginário do feudalismo são apresentadas as novas bases teóricas e metodológicas que 
Duby utilizou para escrevê-la, contando com a colaboração e o apoio de Jacques Le Goff. Nesta obra é explicitado o fato de que a ideologia das três ordens serviu para ocultar os problemas do sistema feudal, havia uma solidariedade triangular para esta ocultação. Assim, toda a sociedade filha do sistema feudal, como o Antigo Regime, possuiria uma estrutura ternária.

No sexto capítulo, denominado Arte, sagrado, sociedade: a sociologia histórica da arte medieval foi apresentada a obra $O$ tempo das catedrais: a arte e a sociedade, onde Duby mostrou uma evolução do conceito de arte no medievo. O monopólio sobre as artes pertencia à Igreja, que era sua transmissora e acreditava que através do artístico poderia se comunicar com o além. A arte eclesiástica apropriou-se da herança cultural romana e da Renascença carolíngia.

No final da Idade Média, com a nova onda de invasões "bárbaras", o conceito de arte passou por transformações e foram trazidos novos patrimônios culturais à sociedade europeia. Dessa forma, as invasões tiveram um caráter destrutivo e criador, pois ao mesmo tempo em que causaram destruição trouxeram consigo novas significações artísticas. Contudo, surgiram novos promotores da arte e seu monopólio saiu das mãos da Igreja. Paris passou a ser então um modelo cultural a ser seguido e buscou-se a construção de uma unidade europeia e das formas artísticas resultantes da concentração de poderes que as casas reais começaram a realizar.

No sétimo capítulo, Recepções de Georges Duby, Milton C. Costa buscou analisar as reações de filósofos e historiadores com a produção histórica de 188 Georges Duby. Este capítulo divide-se em duas partes: a primeira mostrando as perspectivas filosóficas e, a segunda, visões historiográficas. Na primeira são citadas as análises de Guy Lardreau, Nilo Odália e François Dosse, em que cabem grandes elogios à produção historiográfica de Duby como um sintetizador de duas grandes tradições históricas: a dos Annales e a marxista.

Em seguida, nas visões historiográficas, são apresentadas as leituras de Beatriz Rojas, Jacques Dalarun e Aaron Guriêvitch. Rojas tece fortes elogios à união da História com a Geografia desenvolvida por Duby. Jacques Dalarun percebeu que existia uma unidade na produção histórica do medievalista e o considera o revelador da psicologia dos homens medievais. Já Aaron Guriêvitch faz severas críticas à produção de Duby por considerá-la demasiadamente preocupada com a cronologia, excessos de idealizações e sociologismo, assim como a realização de uma história aristocrática e cavaleiresca.

Nos dois últimos capítulos, Contrapontos (1): Georges Dubyea medievalística contemporânea e Contrapontos (2): o itinerário historiográfico de Jacques Le Goff, Milton C. Costa apresentou as recepções da produção historiográfica de Duby para os historiadores de seu tempo. No primeiro mostrou a influência dos grandes mestres dos Annales (Bloch, Febvre e Braudel) na escrita histórica do medievalista e as suas recepções por eles e outros historiadores. No segundo apresentou à ruptura da produção de Duby a partir da obra As três ordens, a qual se aproxima da Nova História defendida por Jacques Le Goff.

Em suas considerações finais, Milton C. Costa defendeu que Duby foi responsável por uma expressiva revolução historiográfica no século XX (p. 351), 
pois uniu grandes tradições historiográficas em sua produção, além de participar das transições das gerações dos Annales. O livro Compreender Georges Duby, mais do que apresentar de forma magistral a produção historiográfica deste historiador, é um convite para conhecermos mais profundamente sua vida e produção acadêmica. Apoiando-se em diferentes fontes - criando uma obra ímpar e rica - Milton C. Costa mostrou que Georges Duby é um historiador atual e que merece estar presente nas prateleiras dos historiadores das mais diversas temáticas. 